\title{
Urban-induced changes in tree leaf litter accelerate decomposition
}

\author{
Jens Dorendorf ${ }^{1 *}$, Anja Wilken ${ }^{1}$, Annette Eschenbach $^{2}$ and Kai Jensen ${ }^{1}$
}

\begin{abstract}
Introduction: The role of urban areas in the global carbon cycle has so far not been studied conclusively. Locally, urbanization might affect decomposition within urban boundaries. So far, only few studies have examined the effects of the level of urbanization on decomposition.

This study addresses the influence of the level of urbanization on decomposition processes. It explores whether potential influences are exerted through leaf litter quality alterations or through direct effects of decomposition site's level of urbanization. Leaf litter of five different tree species was sampled at urban and periurban sites.

Decomposition of this litter was analyzed in three different experiments: a climate chamber incubation, a reciprocal litterbag transplant at urban and periurban sites, and a common garden litterbag transplant.

Results: Decomposition site's level of urbanization did not show a significant effect. However, in all species, when significant differences were observed, leaf litter of urban origin decomposed significantly faster than leaf litter of periurban origin. This effect was observed in all three experiments. In the reciprocal litter transplant experiment, $62 \% \pm 3 \%$ mass loss in litter of urban origin compared to $53 \% \pm 3 \%$ in litter of periurban origin was observed. The difference was not as pronounced in the other two experiments, with $94 \% \pm 1 \%$ mass loss of litter originating in urban habitats compared to $92 \% \pm 1 \%$ mass loss of litter originating in periurban habitats in the common garden experiment and $225 \pm 13 \mathrm{mg} \mathrm{CO}$ released from litter originating in urban habitats compared to $200 \pm 13 \mathrm{mg} \mathrm{CO}_{2}$ released from litter originating in periurban habitats in the climate chamber incubation.
\end{abstract}

Conclusions: We conclude that the level of urbanization affects decomposition indirectly through alterations in leaf litter quality even over short urban to periurban distances.

Keywords: Litterbags; Urban gradients; Carbon cycling; Mass loss; Respiration; Urban ecology; Urban forests; Paired studies; Suburban; Urban-rural contrast

\section{Introduction}

Urban areas play a crucial role in anthropogenic climate change. Due to the high number of people living in cities (more than half of the world's population, UN 2011), cities can be considered 'hot spots' for the release of $\mathrm{CO}_{2}$ (Grimm et al. 2008). Urban areas, however, not only are sources of $\mathrm{CO}_{2}$ but also store substantial amounts of organic carbon in trees and soils (Churkina et al. 2010). Moreover, cities not only affect the global carbon cycle through anthropogenic release of $\mathrm{CO}_{2}$ and storage of organic carbon but have long been observed to influence decomposition (e.g., Fenn and Dunn 1989). As urban

\footnotetext{
* Correspondence: jens.dorendorf@uni-hamburg.de

'Applied Plant Ecology, Biocenter Klein Flottbek, Universität Hamburg,

Ohnhorstraße 18, 22609 Hamburg, Germany

Full list of author information is available at the end of the article
}

areas cover substantial amounts of the earth's land surface (with estimates up to 3.52 million $\mathrm{km}^{2}$, Potere and Schneider 2007), the influence of urban areas on decomposition processes is of interest beyond individual city limits. This is especially true for carbon sequestration modeling in residential landscapes (e.g., Zirkle et al. 2012).

Decomposition is a key component in the carbon cycle, as carbon bound in biomass is either released into the atmosphere as $\mathrm{CO}_{2}$ or stabilized by humification processes into long-lived soil organic matter. The process of decomposition is complex and includes, for example, ingrowth of microbial biomass and nutrient accumulation in addition to leaching and respiration. Here, the term decomposition is used to describe the net mass loss of biomass (Berg and McClaugherty 2008).

\section{实 Springer}


Decomposition is influenced by abiotic environmental conditions, decomposer communities, and the quality of decomposing material (Berg and McClaugherty 2008). All of these factors can be altered by the level of urbanization. Abiotic environmental conditions shown to be influenced by the level of urbanization are raised temperatures (urban heat island (UHI), Oke 1973) and increased precipitation in and downwind of cities (Schlünzen et al. 2010). Decomposer communities have been shown to be influenced by the level of urbanization due to heavy metal deposition (Cotrufo et al. 1995) and introduction of non-native soil fauna (Steinberg et al. 1997). The quality of decomposing material can be altered in numerous chemical parameters known to influence decomposition processes (e.g., $\mathrm{N}$ content), with significant interspecific differences in alterations (Carreras et al. 1996; Alfani et al. 2000). As some alterations due to the level of urbanization might have an accelerating effect on decomposition, while others might have a decelerating one, predicting the net effect of the level of urbanization on decomposition is challenging and empirical data is scarce.

Following the model of a concentric city, with a heavily urbanized inner city and a gradually decreasing level of urbanization towards the city's fringes (Wittig et al. 1998), distance to city center can be used as an approximated, inversed urbanization gradient. Employing gradients or paired studies from inner city study sites to study sites at a city's fringes or even in the rural hinterlands has been pointed out as a valuable possibility to study the ecological impact of urbanization (McDonnell and Pickett 1990).

So far, the impact of the level of urbanization on decomposition has only been studied in few cities around the globe and results are contradictory. Leaf litter alterations in litter originating from urban habitats in Naples as well as in New York City led to a slower decomposition (Cotrufo et al. 1995; Carreiro et al. 1999; Pouyat and Carreiro 2003), while litter from Helsinki decomposed faster (Nikula et al. 2010) compared to the respective litter of rural origin. Environmental and soil alterations at urban sites led to an accelerated mass loss of litter in New York City and Helsinki (Pouyat et al. 1997; Pouyat and Carreiro 2003; Nikula et al. 2010), while a decelerated mass loss has been observed at urban sites in Naples as well as in Asheville, NC, USA (Cotrufo et al. 1995; Pavao-Zuckerman and Coleman 2005) compared to the respective rural sites. Still other studies found no effect on decomposition, neither of the decomposition site's level of urbanization nor of leaf litter origin site's level of urbanization (Carreiro et al. 2009). Since results of previous studies are contradictory and cities around the globe differ drastically, e.g., in their structure and pollution regime, more research in various cities is needed to detect general trends in the influence of urbanization on decomposition. The study at hand examines the effects of level of urbanization on decomposition in the city of Hamburg, Germany, either through alterations in leaf litter quality or conditions at the decomposition site.

Moreover, the study examines decomposition of leaf litter of five different tree species. Until now, individual studies have solely been conducted with leaf litter of a single species (e.g., Pouyat et al. 1997). As species or even variants of the same species differ in their reaction to urbanization (Carreras et al. 1996), potentially leading to differently altered decomposition processes, this study includes leaf litter of five tree species to enable interspecific comparisons. Chosen species are common in the study area and attention was paid to include species with differing ecology, namely with and without symbiosis with dinitrogen $\left(\mathrm{N}_{2}\right)$-fixing bacteria, and native as well as non-native species. To compare results between cities without the confounding influence of interspecific differences, this study includes two species previously studied in other cities (Populus tremula in Helsinki and Quercus rubra in New York City) (Carreiro et al. 1999; Pouyat and Carreiro 2003; Nikula et al. 2010).

Marked differences exist between early and late stages of leaf litter decomposition (Berg and McClaugherty 2008). Simplified, in early stages of decomposition, non-lignified compartments of litter are decomposed as they are easily accessible to microorganisms (Berg and McClaugherty 2008). This process is accelerated by high litter $\mathrm{N}$ content and decelerated by high lignin content (Berg and McClaugherty 2008). In later stages, this relation is reversed, the overall decomposition rate is slowed, and a high lignin and low $\mathrm{N}$ content are related to a relatively faster and more complete decomposition (Berg and McClaugherty 2008). To analyze different stages of decomposition in a limited amount of time, three different methods were employed: a climate chamber incubation focusing on early stages of decomposition, a reciprocal litter transplant expected to show intermediate mass loss values (intermediate stage), and a common garden experiment with elevated temperature and humidity expected to lead to high mass loss values (late stage).

This study aims to (1) analyze whether origin of tree leaf litter (urban vs. periurban, respective city center vs. city fringe) affects its decomposition over a short distance. Further, the study (2) examines direct influences of decomposition sites (urban vs. periurban) on mass loss by comparing decomposition at urban and periurban sites including field measurements of the site conditions. These questions are addressed in combination with (3) evaluating interspecific differences in decomposition between the five chosen species and the respective influences of the level of urbanization. Additionally, it (4) compares results of the three employed methods representing different stages of decomposition. 


\section{Methods \\ Study site}

Hamburg, Germany, is located in northern Europe (53 ${ }^{\circ}$ $\left.38^{\prime} \mathrm{N}, 10^{\circ} 0^{\prime} \mathrm{E}\right)$ and home to about 1.8 million inhabitants (Statistisches Amt für Hamburg und Schleswig-Holstein 2013). In addition to typical inner city built-up, the city's $755 \mathrm{~km}^{2}$ include various land uses, e.g., grasslands and agriculture. Its climate is temperate oceanic with $749 \mathrm{~mm}$ of precipitation annually and an average annual temperature of $8.8^{\circ} \mathrm{C}$ for the years from 1891 to 2007 (Hoffmann and Schlünzen 2010). An urban heat island of inner city sites of about $1.0 \mathrm{~K}$ and a $5 \%$ to $20 \%$ increased precipitation compared to areas $43 \mathrm{~km}$ downwind of the urban center have been determined (Schlünzen et al. 2010; Wiesner et al. 2014).

\section{Collection of leaf litter and analyzed species}

Air-dried, senescent leaf litter samples of five different tree species were used for this study. Species include native Acer platanoides, Alnus glutinosa, and Populus tremula and non-native Quercus rubra and Robinia pseudoacacia. Of these, Alnus as well as Robinia live symbiotically with $\mathrm{N}_{2}$-fixing bacteria. All species are common to the study area.

To sample trees of urban and periurban origin, ten individual trees per species were sampled in the city's center and at its periphery. To find individual sample trees, we used the tree cadaster of Hamburg's Office for Urban Planning and Nature. The urban and periurban sites were chosen as to include a sufficient number of individuals of each species within a reasonable distance of one another. Thus, the urban sites were located about $3 \mathrm{~km}$ north and the periurban sites about $11 \mathrm{~km}$ east of the city hall. The term 'urban' has so far not been defined comprehensively (Raciti et al. 2012). Neither has the term 'periurban', used here to describe areas between urban center and rural hinterlands. Periurban sample sites in our study were located in districts of Hamburg with a relatively high population density and a mixture of large open spaces, rural lots, major roads, and industrial complexes. Fifty individual trees at both sites were selected with the objective of growing in rather free ground in parks or green strips of varying sizes and ages, but not in small roadside tree-planting spaces. According to data obtained from the German Meteorological Service (DWD), urban tree sites have a higher mean temperature and lower mean precipitation than periurban tree sites $\left(9.5^{\circ} \mathrm{C}\right.$ and $753 \mathrm{~mm}$ compared to $9.0^{\circ} \mathrm{C}$ and $784 \mathrm{~mm}$, respectively). Additionally, districts harboring urban sites had a higher mean population density than the periurban ones $(11,000$ people per $\mathrm{km}^{2}$ and 4,000 people per $\mathrm{km}^{2}$, respectively) (Statistisches Amt für Hamburg und Schleswig-Holstein 2012). Though no direct measurements of air quality, e.g., $\mathrm{O}_{3}$ concentration, were conducted at the tree sites, differences in air chemistry can be expected between them (Freie und Hansestadt Hamburg 2012).

Leaf litter was collected off the ground in October 2011 and air-dried (Of the sampled trees, two urban Acer and one urban Populus were determined to be of another species during this step and their litter excluded). Petioles of litter were discarded and litter was torn into pieces of about 3-cm diameter to ease subsequent filling of litterbags. Subsequently, litter was pooled according to species and origin of leaf litter, i.e., urban and periurban tree locations, yielding ten pools in total.

\section{Litterbag experiments}

Litterbags were constructed from PVC-coated fiberglass fly-screen with a mesh size of $1.2 \mathrm{~mm} \times 1.4 \mathrm{~mm}$ by heat welding, allowing access of soil microorganisms to the litter, but excluding macrofauna (Swift et al. 1979). Litterbags were square-shaped with $15-\mathrm{cm}$ side length and were filled with about $2.00 \mathrm{~g}$ of the pooled, air-dried litter. Litter mass as well as mass of litter residues was determined with a two-decimal accuracy to calculate relative percent mass loss (see below).

Two correction factors were established for mass of initial litter. One was a species-specific air-dried to oven-dried correction factor, obtained by dividing the mass of five litter subsamples dried at $105^{\circ} \mathrm{C}$ for $48 \mathrm{~h}$ per species by their initial air-dried weight. The other was a decomposition site (see below)-specific travelbag factor, accounting for litter fragments lost due to handling and transport. Travelbags were constructed in the same way as other litterbags and were transported to and back from the decomposition site with mass loss due to handling determined subsequently. Twenty-five travelbags were constructed in total and culminated in a mean correction factor of $4 \%$ litter mass lost.

\section{Reciprocal litter transplant experiment}

To assess the effect the level of urbanization has on litter decomposition via litter quality alterations and alterations at the decomposition site, a reciprocal litter transplant experiment was carried out. For litter to reach an intermediate stage of decomposition under near-natural conditions, a duration of 155 to 161 days was chosen after which all litterbags were retrieved at once. Sets of litterbags were deployed in March 2012 at 15 urban and 15 periurban sites and retrieved in August 2012. The 30 sites of decomposition were chosen from the 100 tree sites of litter origin (10 individual trees per species per origin). At each decomposition site, one set of litterbags was set out (Figure 1). Each litterbag set included one bag of all ten pools: each species (Acer, Alnus, Populus, Quercus, Robinia) of each origin (urban, periurban). The ten bags per set were set out next to another with a 


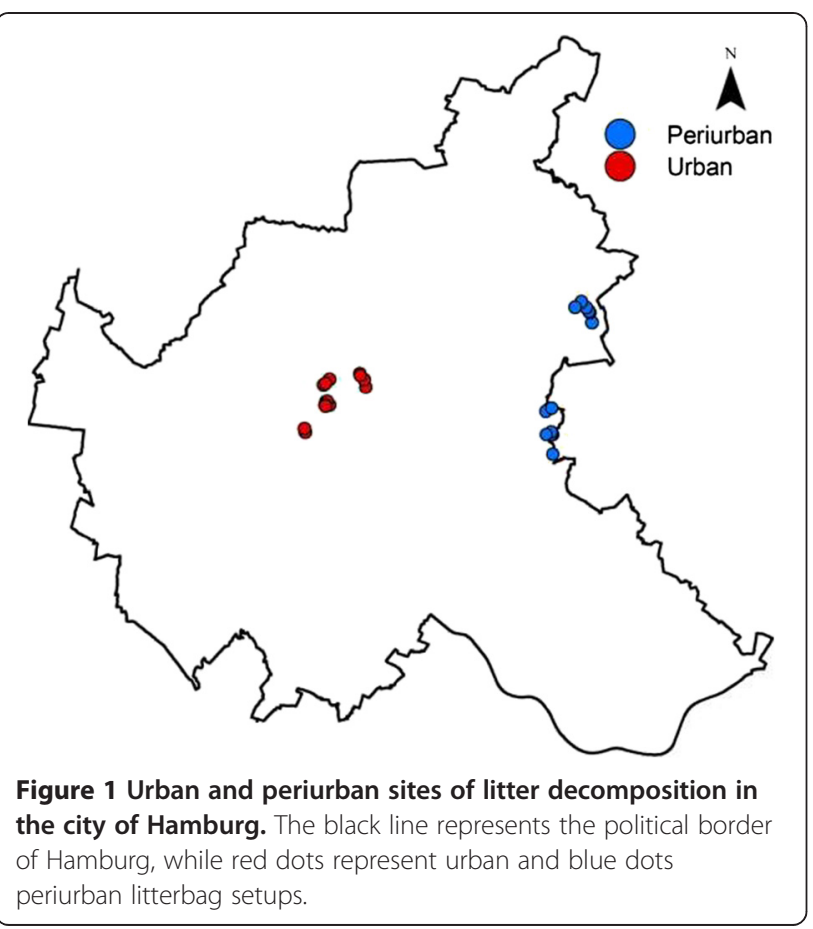

3- to 5-cm gap between them. To prevent disturbance from, e.g., passersby, litterbags were covered with 1 to $5 \mathrm{~cm}$ of soil.

Since sites of decomposition were chosen from the 100 tree sites of litter origin, they were adjacent to the said tree and 'near-natural', meaning parks of various sizes, green strips, or hedgerows. We established a high number of sites (30 in total) to represent the variety of soils and soil covers found at urban and periurban 'nearnatural' sites, though an in-depth analysis of soil types was beyond the scope of this study. Soil cover varied between and within urban and periurban sites from true litter layers, to understory herbs, to bare soil. Sites were shaded by nearby trees and their understory.

While all decomposition sites included litterbags of all five species of both origins, the individual tree at the decomposition site naturally belonged to only one of the species. The assessment of a potential 'home-field advantage' (e.g., Kagata and Ohgushi 2013) (e.g., Acer litter decomposing faster under an Acer tree) was beyond the scope of this study. To prevent 'home-field advantage' from being a confounding factor, three urban and three periurban sites of decomposition were set up per tree species, resulting in an equal number of litterbag sets per tree species, e.g., three sites under an urban and three under a periurban Acer tree and so forth.

After retrieval, litterbags were opened and contents washed to separate litter residues from contaminants, e.g., soil and visible fauna. Afterwards, residues were oven-dried at $105^{\circ} \mathrm{C}$ for $48 \mathrm{~h}$ and weighed.

\section{Soil parameters and leaf litter quality}

To determine soil temperatures at urban and periurban decomposition sites during the reciprocal litter transplant experiment, iButtons ${ }^{\circ}$ (accuracy of $\pm 0.5^{\circ} \mathrm{C}$ and resolution of $0.0625^{\circ} \mathrm{C}$; DS1922L-F5\#, Maxim Integrated, San Jose, CA, USA) were placed in plastic zipper bags and placed alongside the buried litterbags (see above) at $0-$ to $5-\mathrm{cm}$ depth. To determine differences in water content, $\mathrm{pH}$, and salt concentration between urban and periurban decomposition sites, soil cores were taken at all decomposition sites at six dates during the course of the litterbag experiment. To detect possible water shortages during dry periods, sampling dates for taking cores were set to be after at least 3 days without precipitation. The cores were transported to the laboratory in airtight plastic bags and gravimetric water content determined by weight difference before and after drying at $105^{\circ} \mathrm{C}$ for $24 \mathrm{~h}$. Ovendried samples were used to determine $\mathrm{pH}$ in $\mathrm{CaCl}_{2}$ and electrical conductivity in $\mathrm{H}_{2} \mathrm{O}$ with a $\mathrm{pH}$ and conductivity meter (Eijkelkamp 18.28, Eijkelkamp Agrisearch Equipment, Giesbeek, The Netherlands).

All initial leaf litter quality analyses were conducted on air-dried, ground leaf material. Carbon and nitrogen content of litter oven-dried at $105^{\circ} \mathrm{C}$ for $24 \mathrm{~h}$ was determined via $\mathrm{CN}$ analyses (vario MAX CNS elementar, Elementar Analysensysteme GmbH, Hanau, Germany) and content of main nutrients and some trace elements of the same oven-dried litter $(\mathrm{Al}, \mathrm{B}, \mathrm{Ca}, \mathrm{Cr}, \mathrm{Cu}, \mathrm{Fe}, \mathrm{K}$, $\mathrm{Mg}, \mathrm{Mn}, \mathrm{Na}, \mathrm{P}, \mathrm{S}, \mathrm{Zn}$ ) via inductively coupled plasma optical emission spectrometry (iCAP 6300 duo, Thermo Fisher Scientific, Schwerte, Germany). Furthermore, structural carbohydrate content of litter dried at room temperature was determined through subsequent digestion in a fiber analyzer (ANKOM 2000, ANKOM Technology, Macedon, NY, USA) in detergent solutions for neutral and acid detergent fiber (NDF consisting mainly of hemicellulose, cellulose, and lignin; ADF consisting mainly of cellulose and lignin) as well as acid detergent lignin (ADL) as described by the manufacturer (ANKOM 2014a, ANKOM 2014b). As the analytical procedure provided by the manufacturer does not include oven-drying of the samples, possible differences in water content between species and subsequent bias in structural carbohydrate content cannot be excluded. Thus, interspecific comparisons in structural carbohydrate content need to be conducted cautiously.

\section{Common garden litter transplant experiment}

To study mass loss in more advanced, later stages of decomposition in the same time span as the reciprocal litter transplant experiment, a decomposition site with expected accelerated decomposition was chosen. To examine alterations in decomposition based solely on origin of leaf litter and without the influence of differing 
sites of decomposition, 15 sets of litterbags (see above) were placed in an experimental field at the Biocenter Klein Flottbek, Hamburg. To accelerate decomposition, an experimental site known to provide naturally increased soil water contents and to be sun-exposed was chosen. Additionally, the soil was covered by a black, water-permeable fleece, elevating soil temperatures due to a reduced sun light albedo and preventing the growth of weeds. Sets of litterbags were deployed and retrieved and soil parameters measured as described for the reciprocal litter transplant experiment.

\section{Climate chamber incubation}

To assess the effect of the level of urbanization on early stages of litter decomposition via litter chemistry alterations, a climate chamber incubation was carried out. Leaf litter samples pooled by species and origin were incubated under controlled conditions in a dark climate chamber at $21^{\circ} \mathrm{C}$ for 14 days in May 2012 and respired $\mathrm{CO}_{2}$ measured daily. Soil was taken from the experimental field and sieved at $2 \mathrm{~mm}$, its water content was increased to $60 \%$ water holding capacity, and it was allowed to rest for 6 days at $6^{\circ} \mathrm{C}$. Adapting a method by Isermeyer (1952), $1.00 \mathrm{~g}$ of pooled litter was mixed with $50 \mathrm{~g}$ wet soil in 1-L jars, with four replicates per litter pool. Two types of controls were set up with four replicates each, empty jars as blanks to detect possible error and jars containing soil without leaf litter to measure basal respiration.

To follow decomposition, $\mathrm{CO}_{2}$ respired from soil (controls) and soil with litter was trapped in $25 \mathrm{~mL}$ of $\mathrm{NaOH}$ in open plastic containers set into the airtight jars. Containers were changed every $24 \mathrm{~h} ; 0.5 \mathrm{M} \mathrm{BaCl}_{2}$ as well as a few drops of indicator (phenolphthalein) was added to the $\mathrm{NaOH}$ and titrated with $\mathrm{HCl}$ until neutralization. Preliminary experiments had shown rapid decomposition rates during the first days of the experiment. Thus, $0.1 \mathrm{M} \mathrm{NaOH}$ was used during the first 7 days and $0.05 \mathrm{M} \mathrm{NaOH}$ the following, adapting the used $\mathrm{BaCl}_{2}$ (10 and $5 \mathrm{~mL}$, respectively) as well as the $\mathrm{HCl}(0.1$ and $0.05 \mathrm{M}$, respectively). Oxygen supply was given by opening of the jars for changing $\mathrm{NaOH}$ containers. Empty jars (blank controls) found the error of $\mathrm{CO}_{2}$ entering the jars during this step to be negligible (less than $1 \mathrm{mg} \mathrm{CO}$ per day respectively opening, data not shown).

For the climate chamber incubation, decomposition rate for the 14 daily measurements was calculated with an equation adapted from Alef and Nannipieri (1995):

$$
D_{r}=\frac{\left(V_{0}-V\right) \cdot 2.2}{d w \cdot t}
$$

In Equation $1, D_{r}$ is the decomposition rate $\left[\mathrm{mg} \mathrm{CO}_{2} \mathrm{~g}^{-1}\right.$ oven-dry weight of soil amended with litter $\left.\mathrm{h}^{-1}\right], V 0$ the amount of $\mathrm{HCl}$ used for titration in milliliters for soil with litter, $V$ the amount of $\mathrm{HCl}$ used in milliliters for the soil sample (control), $d w$ the oven-dry weight of soil amended with litter in grams, $t$ the incubation time in hours, and 2.2 the conversion factor $(1 \mathrm{ml} 0.1 \mathrm{M} \mathrm{NaOH}$ equals $\left.1 \mathrm{mg} \mathrm{CO}_{2}\right)$. A conversion factor of 1.1 was used for the time of the experiment in which $0.05 \mathrm{M} \mathrm{NaOH}$ was used instead of $0.1 \mathrm{M} \mathrm{NaOH}$.

Additionally, the amount of $\mathrm{CO}_{2}$ released during the incubation time of 14 days of the experiment was calculated with the equation:

$$
D_{t}=\sum\left(V_{0}-V\right) \cdot 2.2
$$

In Equation 2, $D_{t}$ is the total amount of released $\mathrm{CO}_{2}$ after 14 days $\left[\mathrm{mg} \mathrm{CO}_{2} \mathrm{~g}^{-1}\right.$ oven-dry weight of soil amended with litter], $V 0$ the amount of $\mathrm{HCl}$ used for titration in milliliters for soil and litter, $V$ the amount of $\mathrm{HCl}$ in milliliters used for the soil sample (control), and 2.2 the conversion factor $(1 \mathrm{ml} 0.1 \mathrm{M} \mathrm{NaOH}$ equals $1 \mathrm{mg} \mathrm{CO}_{2}$ ). A conversion factor of 1.1 was used for the time of the experiment in which $0.05 \mathrm{M} \mathrm{NaOH}$ was used instead of $0.1 \mathrm{M} \mathrm{NaOH}$.

\section{Data analyses/statistical analyses}

All statistical analyses were conducted in Statistica 9.1 (StatSoft Inc., Tulsa, OK, USA). Prior to ANOVAs, data was visually checked for normal distribution.

\section{Reciprocal litter transplant experiment}

For litterbags employed at urban and periurban sites, differences in mass loss between species, origin of leaf litter, and decomposition site were analyzed with Kruskal-Wallis tests, and the respective interactions with a three-way ANOVA, despite mass loss values being measured in percent. To detect interspecific differences, multiple mean rank comparisons were computed. To detect intraspecific differences with regard to origin of litter and decomposition site, Mann-Whitney tests were performed. Since Populus showed a very pronounced contrast in decomposition between urban and periurban litter originating from urban habitats in the climate chamber incubation experiment (see below), a MannWhitney test was conducted for differences between mass losses of all litter with regard to origin excluding Populus data.

\section{Soil parameters and leaf litter quality}

Mean temperatures, water contents, $\mathrm{pH}$, and electrical conductivities measured at urban and periurban decomposition sites were tested for significant differences via $t$-tests. $\mathrm{pH}$ values were re-exponentiated before calculation of the mean concentration of $\mathrm{H}$ ions, which then was expressed as the negative common logarithm again. 
To test for correlations between mass loss in the reciprocal litter transplant to measured soil parameters and leaf litter chemical properties, linear regressions were computed.

\section{Common garden litter transplant experiment}

For litterbags employed at the experimental field, differences in mass loss between species and origin of leaf litter as well as inter- and intraspecific differences were analyzed accordingly with Kruskal-Wallis and MannWhitney tests as well as multiple mean rank comparisons, and the interactions for species and origin with a two-way ANOVA, despite mass loss values being measured in percent.

\section{Climate chamber incubation}

Decomposition rate was visualized and subsequently tested for differences between species and origin of leaf litter with a repeated measures ANOVA. Additionally, decomposition rate during the time of the experiment with the most rapid decomposition (7 days, beginning after the first $48 \mathrm{~h}$ ) was tested with a separate repeated measures ANOVA as well. A two-way ANOVA was computed to test for differences in the total amount of released $\mathrm{CO}_{2}$ during the 14 days of incubation. Intraspecific differences due to origin as well as interspecific differences were tested for via the Tukey HSD post hoc test. Since Populus showed a stark difference in the amount of released $\mathrm{CO}_{2}$, a two-way ANOVA excluding Populus was computed to test whether differences were solely based on this species.

\section{Results}

\section{Litterbag experiments}

\section{Reciprocal litter transplant experiment}

While origin of leaf litter and species had a significant effect on mass loss ( $p \leq 0.05$ and $p \leq 0.001$, respectively), decomposition site did not $(p \geq 0.1)$ (Figure 2). Litter of urban origin decomposed faster than litter of periurban origin $(62 \% \pm 3 \%$ and $53 \% \pm 3 \%$ mass loss, respectively) (Figure 2a). Despite the pronounced difference found in the climate chamber incubation for Populus with regard to origin (see below), when Populus data were excluded from the analysis, the difference between urban and periurban origin was still significant $(61 \% \pm 3 \%$ and $52 \pm$ $3 \%$ mean mass loss, respectively; data not shown, $p \leq$ $0.05)$. Alnus had the highest $(86 \% \pm 3 \%)$ and Quercus the lowest $(29 \% \pm 4 \%)$ mass loss (Figure $2 \mathrm{c}$ ). In a three-way ANOVA, no significant interactions between factors were found. Significant intraspecific differences in mass loss due to origin of litter or decomposition site were only detected in Robinia with litter originating from urban habitats decomposing faster than litter originating from periurban ones (Figure 3).
Of the employed 300 litterbags, 16 were lost due to disturbance at urban sites (10 of one site and 6 individual litterbags).

\section{Soil parameters and leaf litter quality}

In this investigation, soils of the urban sites had a slightly higher overall mean temperature than periurban ones (about $0.3^{\circ} \mathrm{C}$ ) and contained slightly more water (Table 1). Soil samples of urban sites were slightly less acidic than those of periurban sites, but this difference was not significant (Table 1). However, urban soil samples had a significantly increased electrical conductivity compared to periurban soil samples (Table 1).

Litter showed inter- as well as intraspecific differences in its chemical composition. As it was not possible to test for statistical significance, only few results will be highlighted.

Structural carbohydrates tended to be decreased in urban compared to periurban litter samples (NDF and ADL in four of the five species, ADF in three; Table 2). Alnus and Robinia litter had a higher mean $\mathrm{N}$ concentration $(2.46 \%$ and $1.98 \%$, respectively) than species without $\mathrm{N}_{2}$-fixing symbionts $(0.93 \%$, Table 2$)$. Carbon content was slightly decreased in urban compared to periurban samples in all species (Table 2). Comparisons in most parameters show ambiguous trends, e.g., P content is increased in urban Alnus litter, but decreased in urban Acer litter (Table 2).

Linear regression found no significant relation $(p \geq 0.1)$ between analyzed soil parameters and mass loss of litterbags at the respective sites, but mass loss of litter at urban and periurban sites correlated significantly with leaf litter quality parameters (Table 3 ).

\section{Common garden litter transplant experiment}

As intended, soil at the experimental field site had a higher mean temperature $\left(17.4^{\circ} \mathrm{C}\right)$ and contained more water $(0.33 \mathrm{~g}$ per g dry soil), as well as was less acidic $(\mathrm{pH} 5.7)$ and had a lower electrical conductivity $\left(102 \mu \mathrm{S} \mathrm{cm}^{-1}\right.$ ) than soils at the urban and periurban sites.

As anticipated, mass loss at the experimental field site was higher for all species than that in the reciprocal litter transplant experiment. And in accordance to results at urban and periurban decomposition sites, litter of urban origin decomposed faster than litter of periurban origin $(94 \% \pm 1 \%$ and $92 \% \pm 1 \%$ mass loss, respectively, $p \leq 0.05$ ) (Figure $4 \mathrm{a}$ ). When differences between litter origins were tested for species individually, only Populus showed a significant difference in mass loss $(p \leq 0.01)$ (Figure 4c). When Populus was excluded from the overall analysis of mass loss depending on origin, the difference was almost significant $(94 \% \pm 1 \%$ and $92 \% \pm 1 \%$ 

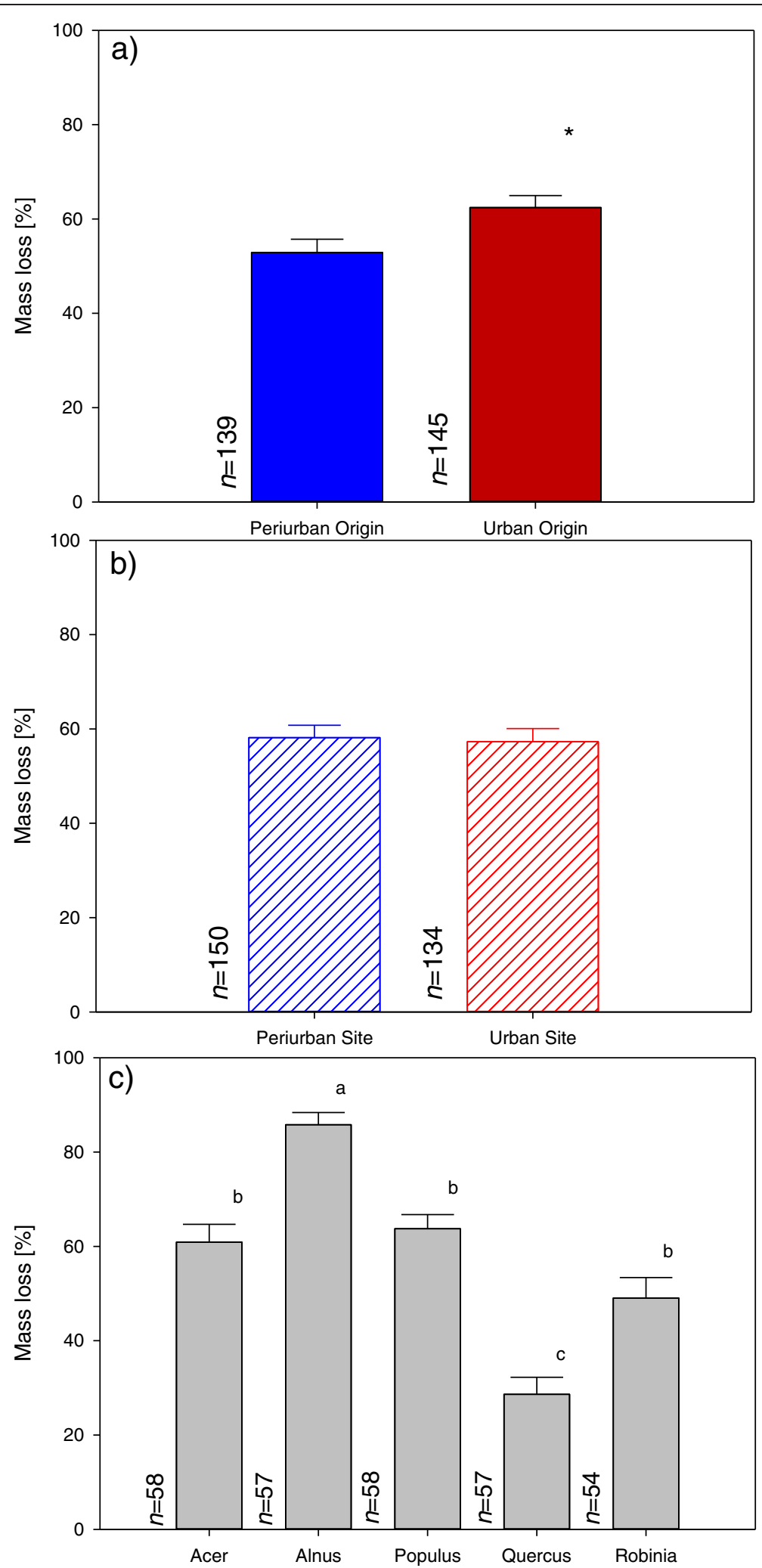

Figure 2 Mass loss of reciprocal litter transplant. Depending on (a) origin of litter, (b) decomposition site, and (c) species. The asterisk indicates significant difference according to the Mann-Whitney test, and different letters indicate pairwise differences according to multiple mean rank comparisons of species' means; differences in $n$ are due to loss of litterbags through disturbance. 

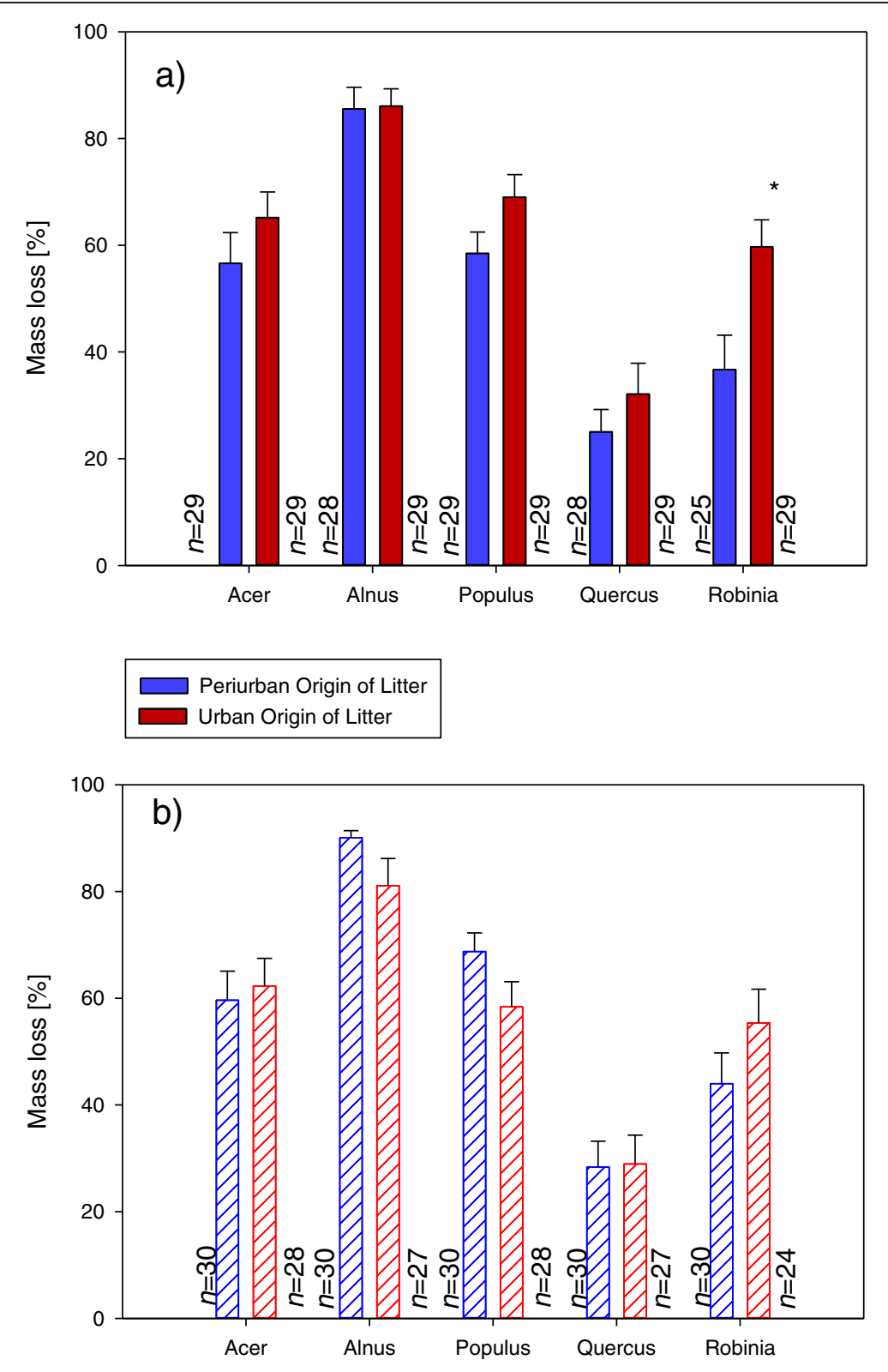

$Z 7 Z$ Periurban Site of Decomposition $Z / Z$ Urban Site of Decomposition

Figure 3 Intraspecific differences in mass loss in the reciprocal litter transplant. Depending on (a) origin of litter and (b) decomposition site. The asterisk indicates significant intraspecific difference according to the Mann-Whitney test; differences in $n$ are due to loss of litterbags.

mass loss, respectively, $p \leq 0.1$; data not shown). Species differed significantly in their mass loss $(p \leq 0.001)$, and post hoc tests revealed that Acer, Alnus, and Populus decomposed faster than Quercus and Robinia (98\% \pm $<1 \%, 99 \% \pm<1 \%, 99 \% \pm<1 \%$ and $78 \% \pm 3 \%, 91 \% \pm 2 \%$, respectively) (Figure $4 \mathrm{~b}$ ). Two-way ANOVA found no interaction between the factors origin of litter and species.

\section{Climate chamber incubation}

Decomposition rate over the entire 14 days of the experiment differed significantly between species $(p \leq$ $0.001)$, origins of leaf litter $(p \leq 0.001)$, and time $(p \leq$ 0.001 ) (Table 4). Decomposition rate of most species increased during the first $48 \mathrm{~h}$ until it gradually decreased (Figure 5). If only the 7 days with the most rapid decomposition were included, decomposition rate still differed 
Table 1 Mean and SE of measured soil parameters

\begin{tabular}{lccc}
\hline & Periurban (SE) & Urban (SE) & $\boldsymbol{p}$ value \\
\hline Temperature $\left[{ }^{\circ} \mathrm{C}\right]$ & $13.0( \pm 0.2)$ & $13.3( \pm 0.1)$ & $<0.1$ \\
Water content $\left[\mathrm{g} \mathrm{g}^{-1}\right.$ soil] & $0.17( \pm 0.01)$ & $0.21( \pm 0.01)$ & $<0.05$ \\
$\mathrm{pH}$ & $4.2(3.4$ to 6.5$)$ & $4.5(3.7$ to 6.2) & n.s. \\
$\mathrm{EC}\left[\mu \mathrm{S} \mathrm{cm}{ }^{-1}\right]$ & $107( \pm 5)$ & $165( \pm 14)$ & $<0.05$ \\
\hline
\end{tabular}

Measured soil parameters (min. and max. for $\mathrm{pH}$ ) over the course of the experiment at the periurban $(n=15)$ and urban $(n=15)$ decomposition sites with the respective $t$-test $p$ values (n.s., not significant).

significantly between species $(p \leq 0.001)$, origin $(p \leq$ $0.001)$, and time $(p \leq 0.001)$ (Table 5$)$. The interaction between species and origin was found to be significant, too $(p \leq 0.001)$ (Table 5). While urban litter tended to decompose faster, Acer and Alnus of urban origin showed a slightly reduced decomposition rate. The symbiotically $\mathrm{N}_{2}$-fixing species Robinia and Alnus had the highest decomposition rates, while Quercus had the lowest.

Total amount of released $\mathrm{CO}_{2}$ after 14 days of incubation differed significantly between species $(p \leq 0.001)$ and origin $(p \leq 0.001)$. The interaction between species and origin was found to be significant as well $(p \leq 0.001)$. Robinia and Alnus showed the highest amount of $\mathrm{CO}_{2}$ and Quercus the lowest (Figure 6b). Including all species, urban litter released more $\mathrm{CO}_{2}$ than periurban litter (Figure 6a). However, Acer and Alnus released slightly less $\mathrm{CO}_{2}$ from urban than from their respective periurban litter (Figure 6c). In contrast, Quercus and Robinia released more $\mathrm{CO}_{2}$ from litter of urban origin and Populus litter of urban origin released almost $40 \%$ more than litter of rural origin (Figure 6c).

Despite the pronounced difference found in the climate chamber incubation for Populus with regard to origin, when Populus was excluded from the analysis, species still differed significantly in the amount of released $\mathrm{CO}_{2}(p \leq 0.001)$. However, while urban litter over the four remaining species still released more $\mathrm{CO}_{2}$ than periurban litter, this difference was only almost significant $(p \leq 0.1)$ with a significant interaction between species and origin $(p \leq 0.05)$.

\section{Discussion}

The study revealed a faster decomposition of litter originating from urban habitats compared to litter originating from

Table 2 Chemical properties of leaf litter pools

\begin{tabular}{|c|c|c|c|c|c|c|c|c|c|c|}
\hline \multirow{2}{*}{$\begin{array}{l}\text { Species } \\
\text { Origin }\end{array}$} & \multicolumn{2}{|c|}{ Acer } & \multicolumn{2}{|c|}{ Alnus } & \multicolumn{2}{|c|}{ Populus } & \multicolumn{2}{|c|}{ Quercus } & \multicolumn{2}{|c|}{ Robinia } \\
\hline & Periurban & Urban & Periurban & Urban & Periurban & Urban & Periurban & Urban & Periurban & Urban \\
\hline NDF [\%] & 50.03 & 59.44 & 37.33 & 36.58 & 37.19 & 33.51 & 58.57 & 55.79 & 26.76 & 25.43 \\
\hline ADF [\%] & 19.09 & 22.75 & 20.50 & 19.60 & 23.52 & 20.52 & 29.63 & 28.56 & 16.48 & 16.85 \\
\hline ADL [\%] & 8.27 & 9.97 & 10.64 & 10.23 & 9.17 & 8.29 & 15.84 & 15.10 & 9.22 & 8.99 \\
\hline$N[\%]$ & 0.98 & 0.94 & 2.49 & 2.42 & 1.07 & 0.91 & 0.77 & 0.90 & 2.07 & 1.90 \\
\hline$C[\%]$ & 44.69 & 44.58 & 48.52 & 47.40 & 45.87 & 45.25 & 49.26 & 48.67 & 46.78 & 44.42 \\
\hline$P\left[\mathrm{~g} \mathrm{~kg}^{-1}\right]$ & 1.39 & 0.54 & 0.53 & 0.92 & 0.95 & 1.23 & 2.28 & 2.22 & 0.75 & 0.91 \\
\hline $\mathrm{S}\left[\mathrm{g} \mathrm{kg}^{-1}\right]$ & 1.57 & 1.54 & 0.98 & 2.11 & 1.75 & 2.96 & 0.75 & 0.95 & 1.64 & 1.56 \\
\hline $\mathrm{K}\left[\mathrm{g} \mathrm{kg}^{-1}\right]$ & 7.61 & 9.58 & 3.81 & 6.66 & 7.51 & 7.36 & 5.16 & 4.00 & 7.48 & 6.98 \\
\hline$C: N$ & 45.68 & 47.32 & 19.45 & 19.62 & 43.05 & 49.70 & 63.88 & 53.86 & 22.60 & 23.39 \\
\hline$C: P$ & 322.07 & 819.58 & 910.18 & 515.11 & 484.83 & 368.17 & 215.74 & 219.64 & 623.43 & 487.71 \\
\hline ADL:N & 8.45 & 10.59 & 4.26 & 4.23 & 8.61 & 9.10 & 20.54 & 16.71 & 4.46 & 4.73 \\
\hline $\mathrm{Al}\left[\mathrm{mg} \mathrm{kg}{ }^{-1}\right]$ & 699.69 & $1,257.62$ & 727.50 & $1,593.08$ & $2,363.85$ & $1,693.85$ & 722.38 & 929.77 & $1,168.62$ & $2,773.85$ \\
\hline $\mathrm{B}\left[\mathrm{mg} \mathrm{kg}^{-1}\right]$ & 140.40 & 165.75 & 46.58 & 119.75 & 176.30 & 207.30 & 76.52 & 77.56 & 103.10 & 138.45 \\
\hline $\mathrm{Ca}\left[\mathrm{g} \mathrm{kg}^{-1}\right]$ & 31.12 & 31.28 & 10.18 & 24.01 & 29.10 & 37.61 & 18.32 & 20.13 & 35.57 & 46.62 \\
\hline $\mathrm{Cr}\left[\mathrm{mg} \mathrm{kg}^{-1}\right]$ & 1.63 & 1.16 & 0.81 & 1.10 & 1.62 & 1.68 & 3.91 & 2.94 & 0.77 & 2.23 \\
\hline $\mathrm{Cu}\left[\mathrm{mg} \mathrm{kg}^{-1}\right]$ & 12.25 & 16.35 & 10.50 & 24.34 & 16.25 & 28.87 & 9.64 & 12.50 & 17.22 & 20.16 \\
\hline $\mathrm{Fe}\left[\mathrm{mg} \mathrm{kg}{ }^{-1}\right]$ & 227.45 & 392.55 & 181.80 & 433.70 & 517.95 & 580.65 & 168.25 & 266.65 & 331.95 & 712.55 \\
\hline $\mathrm{Mg}\left[\mathrm{g} \mathrm{kg}^{-1}\right]$ & 1.90 & 1.96 & 0.87 & 2.14 & 1.49 & 1.42 & 0.95 & 1.08 & 1.32 & 2.11 \\
\hline $\mathrm{Mn}\left[\mathrm{mg} \mathrm{kg}{ }^{-1}\right]$ & 230.80 & 488.55 & 321.78 & 248.00 & 310.80 & 132.75 & 512.60 & 596.30 & 84.79 & 69.91 \\
\hline $\mathrm{Na}\left[\mathrm{mg} \mathrm{kg}^{-1}\right]$ & 253.70 & 326.10 & 294.25 & 789.90 & 355.05 & 307.90 & 383.10 & 410.15 & 374.70 & 465.75 \\
\hline $\mathrm{Zn}\left[\mathrm{mg} \mathrm{kg}^{-1}\right]$ & 186.70 & 139.30 & 73.83 & 190.25 & 738.85 & $1,070.00$ & 86.18 & 163.00 & 74.14 & 74.54 \\
\hline
\end{tabular}

All values on a per litter oven-dry weight basis, except for NDF neutral detergent fiber, ADF acid detergent fiber, and ADL acid detergent lignin which are on an air-dry weight basis $(n=1)$. 
Table $3 \boldsymbol{R}$ of linear regressions between leaf litter quality and mass loss

\begin{tabular}{|c|c|}
\hline Chemical parameter & $R$ \\
\hline NDF [\%] & -0.36 \\
\hline ADF [\%] & -0.51 \\
\hline ADL [\%] & -0.59 \\
\hline $\mathrm{N}[\%]$ & 0.55 \\
\hline C [\%] & -0.29 \\
\hline$P\left[g^{-1}\right]$ & -0.71 \\
\hline $\mathrm{S}\left[\mathrm{g} \mathrm{kg}^{-1}\right]$ & 0.46 \\
\hline $\mathrm{K}\left[\mathrm{g} \mathrm{kg}^{-1}\right]$ & 0.15 \\
\hline$C: N$ & -0.59 \\
\hline$C: P$ & 0.61 \\
\hline ADL:N & -0.71 \\
\hline $\mathrm{Al}\left[\mathrm{mg} \mathrm{kg}^{-1}\right]$ & 0.24 \\
\hline $\mathrm{B}\left[\mathrm{mg} \mathrm{kg}{ }^{-1}\right]$ & 0.23 \\
\hline $\mathrm{Ca}\left[\mathrm{mg} \mathrm{kg}^{-1}\right]$ & -0.04 \\
\hline $\mathrm{Cr}\left[\mathrm{mg} \mathrm{kg}^{-1}\right]$ & -0.69 \\
\hline $\mathrm{Cu}\left[\mathrm{mg} \mathrm{kg}^{-1}\right]$ & 0.45 \\
\hline $\mathrm{Fe}\left[\mathrm{mg} \mathrm{kg}^{-1}\right]$ & 0.30 \\
\hline $\mathrm{Mg}\left[\mathrm{g} \mathrm{kg}^{-1}\right]$ & 0.41 \\
\hline $\mathrm{Mn}\left[\mathrm{mg} \mathrm{kg}^{-1}\right]$ & -0.34 \\
\hline $\mathrm{Na}\left[\mathrm{mg} \mathrm{kg}^{-1}\right]$ & 0.27 \\
\hline $\mathrm{Zn}\left[\mathrm{mg} \mathrm{kg}^{-1}\right]$ & 0.21 \\
\hline
\end{tabular}

Italicized values indicate $p<0.05$; all values on a per litter oven-dry weight basis, except for NDF neutral detergent fiber, ADF acid detergent fiber, and $A D L$ acid detergent lignin which are on an air-dry weight basis.

periurban habitats. The level of urbanization of the decomposition site did not show significant effects. Species showed differences in their decomposition, but the general trend of accelerated decomposition of litter originating from urban habitats was observed over all species. Due to methodological limitations, we cannot safely say that the accelerated decomposition of litter originating in urban habitats is maintained in the late stages of decomposition.

\section{Origin of leaf litter}

Leaf litter origin had a significant influence on decomposition, with litter grown on trees in urban areas exhibiting an accelerated mass loss. Mass loss in litterbags at urban and periurban sites was significantly and negatively correlated to ADL:N ratio, phosphorus content, and chrome content of initial litter. Nikula et al. (2010) found similar results in Helsinki and listed the higher nitrogen, phosphorus, and base cation as well as the lower lignin, total phenolics, $\mathrm{C}: \mathrm{N}$, and lignin: $\mathrm{N}$ contents and ratios of litter originating from urban habitats as possible reasons for its accelerated decay. Contrary, a decelerated decomposition of litter originating in urban habitats compared to litter originating in rural habitats has been observed in New York City (Carreiro et al. 1999; Pouyat and Carreiro 2003). Here, lignin and NDF content of initial litter were found to be negatively correlated with decay rates (Carreiro et al. 1999). A decelerated decomposition of litter originating from urban habitats was also observed in Naples and London and attributed to increased heavy metal deposition on leaves of urban origin (Cotrufo et al. 1995; Post and Beeby 1996).

Results suggest that leaf litter quality plays a crucial role in the accelerated decomposition of litter originating from urban habitats, and litter quality has been postulated as a dominant factor of decomposition under favorable weather conditions (Coûteaux et al. 1995). Alterations in leaf litter due to the level of urbanization seem to either enhance the nutrient supply to decomposer communities or nutrients are easier accessible due to lower lignin contents (Berg and McClaugherty 2008). Surprisingly, though a correlation of decomposition to litter quality parameters was found in our investigations, these parameters are not altered consistently across the analyzed species. While we found a trend towards decreased structural carbohydrates (NDF, ADF, ADL) in litter originating from urban habitats, neither of the parameters we found to be negatively correlated to mass loss (ADL:N, P, Cr) consistently showed lower values in litter originating from urban habitats (Table 2). This underlines the complex nature of decomposition processes, where individual parameters' predictive values show interspecific differences as well as differences in the various stages of decomposition (Prescott 2010). Further, it has to be kept in mind that the fact of correlation not implying causality holds true also for the relation of litter quality parameters and decomposition (Prescott 2010). Contrary to results from urban sites in Naples (Cotrufo et al. 1995) and London (Post and Beeby 1996), polluted with high concentrations of heavy metals, the difference in airborne heavy metal loads between urban and periurban tree locations in the city of Hamburg was not pronounced enough to delay decomposition of litter originating from urban habitats.

\section{Influence of decomposition site}

No significant difference in mass loss between periurban and urban decomposition sites and no significant correlation of mass loss to measured environmental parameters were found. Previous studies that found an acceleration of decomposition in urban areas attributed their findings to higher temperatures (Pouyat et al. 1997; Pouyat and Carreiro 2003; Nikula et al. 2010), introduced, non-native earthworms with no earthworms present at the respective rural sites (Pouyat et al. 1997; Pouyat and Carreiro 2003), or increased N deposition (Nikula et al. 2010). Studies that found a deceleration of decomposition at urban sites linked it to increased heavy 

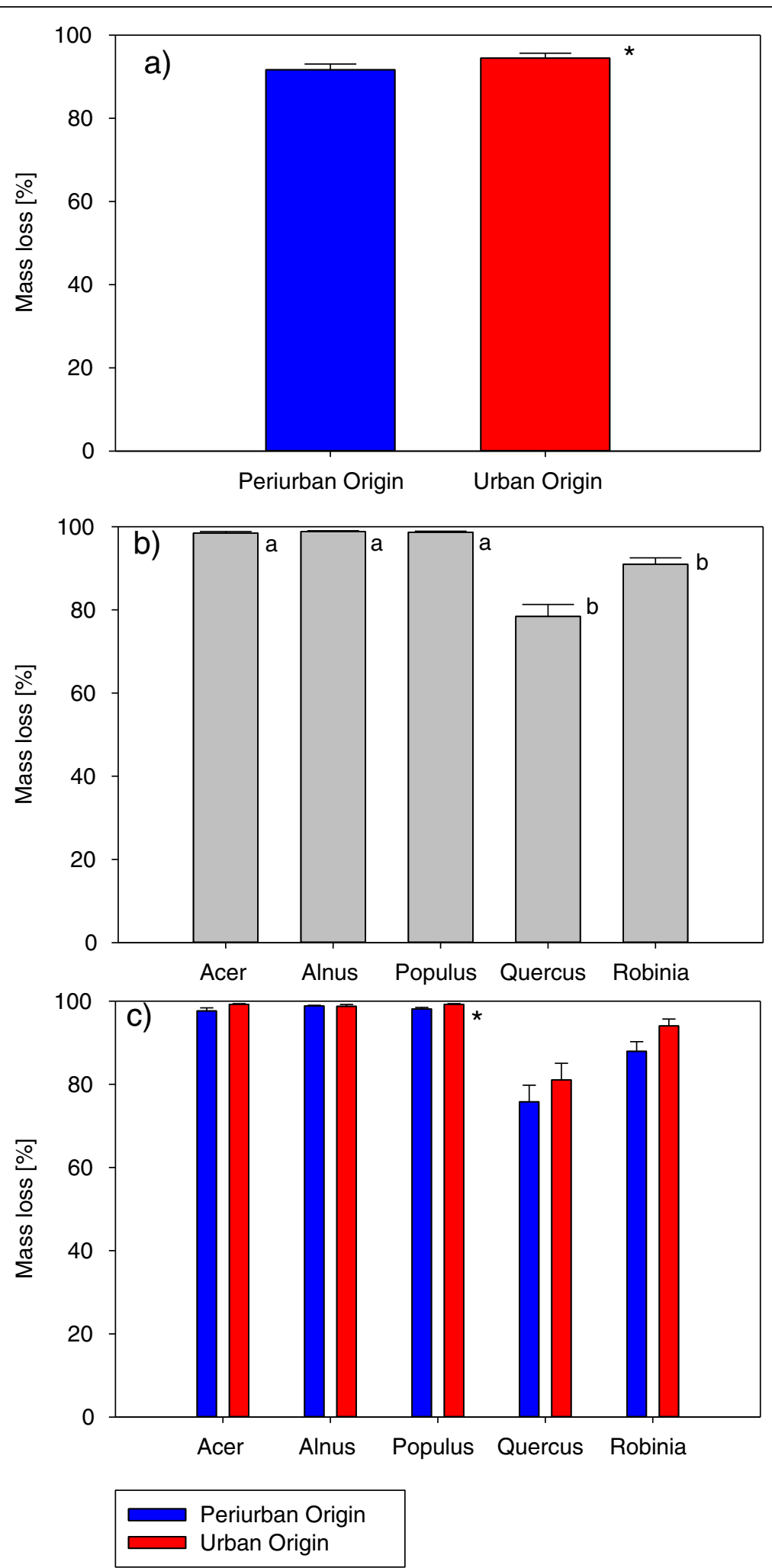

Figure 4 Mass loss in the common garden litter transplant. Depending on (a) origin of leaf litter $(n=75)$ and (b) species $(n=30)$ and (c) showing intraspecific differences $(n=15)$. Asterisks indicate significant differences according to the Mann-Whitney tests, and different letters indicate different species' means according to multiple mean rank comparisons. 
Table 4 Repeated measures ANOVA results for rate of respired $\mathrm{CO}_{2}$ in the 14-day climate chamber experiment

\begin{tabular}{lcc}
\hline & $\boldsymbol{F}$ & $\boldsymbol{p}$ \\
\hline Species & 111 & $<0.001$ \\
Origin & 20 & $<0.001$ \\
Species $\times$ origin & 9 & $<0.001$ \\
Time & 1,527 & $<0.001$ \\
Time $\times$ species & 60 & $<0.001$ \\
Time $\times$ origin & 7 & $<0.001$ \\
\hline
\end{tabular}

metal pollution (Cotrufo et al. 1995) or decreased soil moisture (Pavao-Zuckerman and Coleman 2005).

In our study, soil temperature at urban sites was only slightly higher (mean $0.3^{\circ} \mathrm{C}$ ) than soils at the periurban sites, while a $2^{\circ} \mathrm{C}$ to $3^{\circ} \mathrm{C}$ higher temperature at urban locations was cited in New York City litterbag studies (Pouyat et al. 1997; Pouyat and Carreiro 2003). Assuming a $Q_{10}$ of two (Raich and Schlesinger 1992), the temperature difference in the New York City litterbag studies explained a $20 \%$ to $30 \%$ increased decomposition at the urban sites (Pouyat et al. 1997; Pouyat and Carreiro 2003), while the temperature difference in the
Table 5 Repeated measures ANOVA results for rate of respired $\mathrm{CO}_{2}$ in rapid-respiring 7 days of incubation

\begin{tabular}{lcc}
\hline & $\boldsymbol{F}$ & $\boldsymbol{p}$ \\
\hline Species & 81 & $<0.001$ \\
Origin & 26 & $<0.001$ \\
Species $\times$ origin & 10 & $<0.001$ \\
Time & 760 & $<0.001$ \\
Time $\times$ species & 27 & $<0.001$ \\
Time $\times$ origin & 8 & $<0.001$ \\
\hline
\end{tabular}

present study would merely accelerate decomposition by $3 \%$.

Opposing findings in Asheville, where urban soils contained less water, leading to a decelerated decomposition (Pavao-Zuckerman and Coleman 2005), in our study no limitation of decomposition through water shortage at urban or periurban sites seems likely.

The higher electrical conductivity (EC) at urban sites indicates higher soil salt concentrations and likely stems from higher inputs of de-icing salts in urban areas. Despite being increased, EC values at urban sites were still low, but a direct influence of salt

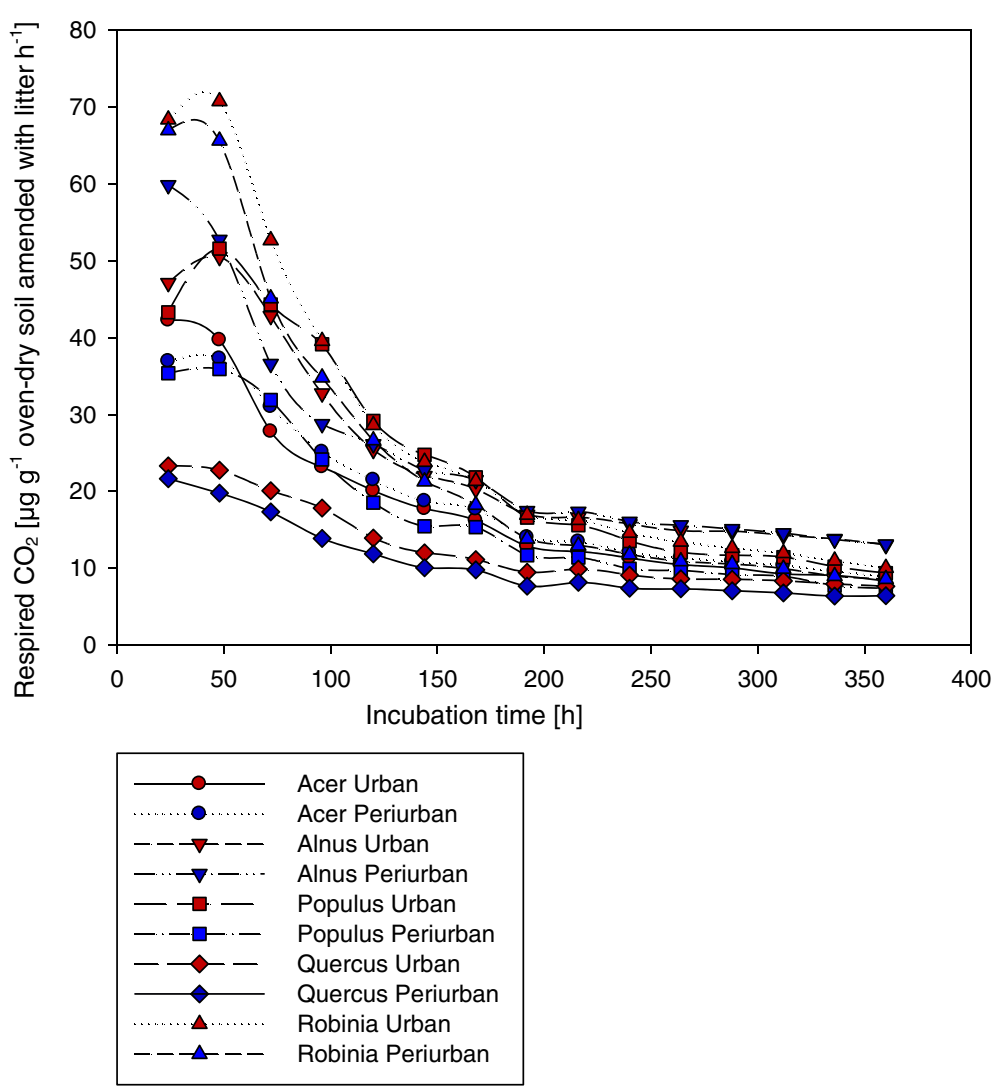

Figure 5 Mean respiration rate in the climate chamber incubation. In CO2 [ug] per g dry soil amended with litter per hour for all species of both origins $(n=4$, except for Robinia periurban where $n=3)$. Identical soil with naturally occurring carbon and biomass was used for all species. 

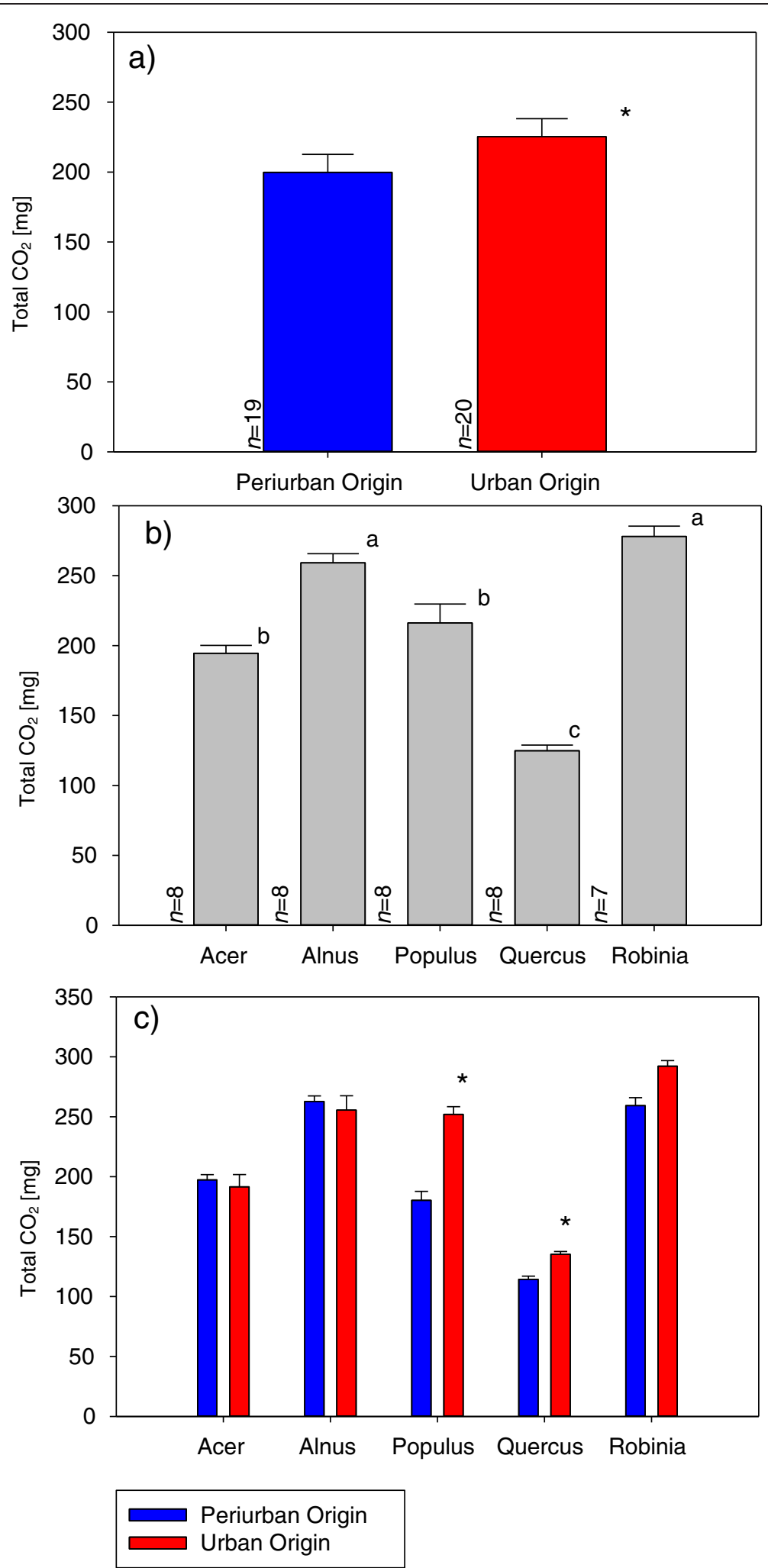

Figure 6 Differences in total amount of respired $\mathrm{CO}_{2}$ in the 14-day climate chamber incubation. With regard to (a) origin of leaf litter, (b) species, and (c) both ( $n=4$, except for Robinia periurban where $n=3$ ). Asterisks indicate significant differences due to origin of litter, and different letters indicate different species' means according to post hoc tests. 
concentration on decomposer organisms cannot be ruled out (Czerniawska-Kusza et al. 2004).

A high abundance of non-native earthworms was found in New York City (Steinberg et al. 1997), and this was considered a main reason for the accelerated decomposition at urban compared to rural sites. Since earthworms are not native to the New York City area, rural sites were without earthworms as they lacked introduced species. Contrary, juvenile worms of introduced species at the urban sites were able to access litter through the litterbags' mesh (Pouyat et al. 1997; Pouyat and Carreiro 2003). In Hamburg, introduction of non-native species does not seem to be as pronounced and native earthworms are common in urban as well as in rural areas. Currently, a relevant influence of non-native earthworms on decomposition processes in the city of Hamburg does not seem likely.

Alterations in environmental and soil parameters between urban and periurban sites of this study were apparently not strong enough to significantly affect decomposition processes. The difference of our study results to previous studies most likely stems from the very short distance of about 10 to $17 \mathrm{~km}$ employed (compared to, e.g., $130 \mathrm{~km}$ between urban and rural sites in New York City, Pouyat and Carreiro 2003). The rapid decomposition at the common garden experiment with its drastically different environment (higher temperature, higher humidity, lower acidity, and lower electrical conductivity than at the urban and periurban decomposition sites) highlights that more pronounced environmental alterations would result in a significantly affected decomposition.

\section{Differences between species}

No pronounced difference in species' reaction to the level of urbanization was observed. When significant intraspecific differences in the reciprocal litter transplant, the common garden litter transplant, and the total amount of respired $\mathrm{CO}_{2}$ in the climate chamber incubation experiment were determined, litter originating from urban habitats decomposed faster than the periurban counterpart. However, the significant interaction in the climate chamber incubation ANOVA between species and origin of litter points towards differences in species' reaction to the level of urbanization, though these are not significant when species are analyzed individually.

In the climate chamber incubation experiment, the litter of symbiotically $\mathrm{N}_{2}$-fixing species Alnus and Robinia released most $\mathrm{CO}_{2}$, while Quercus litter with its high amount of lignin released the least. Considering the litterbag experiments as advanced stages of decomposition, mass loss of Robinia litter seems to decelerate relative to the other species, while mass loss of Alnus litter increases similar to the not symbiotically $\mathrm{N}_{2}$-fixing species compared to early-stage decomposition. The high $\mathrm{N}$ content of Alnus and Robinia litter was expected to initially accelerate decomposition, but as decomposition progresses, it was expected to act as a retarding factor (Berg and McClaugherty 2008). A possible explanation for the deviating result of high mass loss of Alnus litter in the common garden experiment could be that the chosen mesh size of litterbags is only suitable for earlystage decomposition. Potentially, as decomposition progresses, litter parts that are not truly decomposed (i.e., respired) but solely fragmented are lost through the mesh and render the method unreliable. This would imply that results for late-stage decomposition derived from litterbag experiments might be less reliable for any of the analyzed species. This is worth considering especially for extremely small partially decomposed litter fragments and humic substances.

Individual species' leaf litter decomposition can be affected differently by different cities. Contrary to results from New York City (Carreiro et al. 1999; Pouyat and Carreiro 2003), Q. rubra litter decomposed faster in the climate chamber incubation when originating from urban locations. While this difference was only significant in the climate chamber incubation, the same trend was observed in the litterbag experiments. P. tremula leaf litter decomposition was affected in similar ways in Helsinki and Hamburg, with litter originating from urban habitats showing a faster decomposition (Nikula et al. 2010).

The different employed methods yielded similar results, with litter originating from urban habitats decomposing faster. However, all methods have specific advantages and disadvantages. While litterbag experiments are timeconsuming and decomposition site setups in urban areas have a high potential for disturbance, they yield valuable insights into decomposition processes in a near-natural environment. Their biggest advantage is the possibility to examine the effects of the level of urbanization at the decomposition site. However, as seen in the common garden experiment, loss of only partly decomposed material from the litterbags through the mesh can become a problem as decomposition progresses. If only the effect of litter origin is to be studied, climate chamber incubations are a fast alternative.

\section{Conclusions}

We were able to detect an effect of the level of urbanization on decomposition processes. This effect is exerted through alterations in leaf litter quality and not through alterations at the site of decomposition. Other studies also determined an effect of the level of urbanization on decomposition processes through leaf litter alterations. However, found results partly contradict previous findings, where litter of urban origin was often found to exhibit a decelerated decomposition. Further, 
previous studies often observed an effect due to the level of urbanization of the site of decomposition.

The effect the level of urbanization has on decomposition processes can so far not be characterized globally. Through including five species in our study, we were able to differentiate the effects the level of urbanization has on decomposition in more detail than previous studies. While we found some interspecific difference, the overall effect the level of urbanization has on decomposition processes was similar across species. Due to the partly contradiction to previous findings, we conclude that the effects the level of urbanization has are complex and vary between cities. Further studies are needed to pinpoint the underlying mechanisms responsible for the differing observations in various cities.

\section{Competing interests}

The authors declare that they have no competing interests.

\section{Authors' contributions}

JD conceptualized, designed, and carried out the mentioned studies; analyzed and interpreted the data; and drafted the manuscript. AW carried out the climate chamber incubation and analyzed and interpreted the respective data. $\mathrm{AE}$ and $\mathrm{KJ}$ supported the conceptualization and design of studies as well as the analysis and interpretation of data and have revisited the manuscript critically for important intellectual content. All authors read and approved the final manuscript.

\section{Acknowledgements}

We thank the Bauer-Stiftung in the Stifterverband für die Deutsche Wissenschaft and the Deutsches Stiftungszentrum for funding. For data provision and support, we would like to thank the Office for Urban Planning and the Environment of Hamburg. We thank the graduate school SICSS for the assistance of J. Dorendorf. Valuable support was received by the staff at Biocenter Klein Flottbek and Institute for Soil Sciences at the University of Hamburg. Further thanks go towards the staff at the Biocenter Grindel for their help in the analysis of structural carbohydrates. Notably, we thank Lars Kutzbach. We thank the Thünen Institute of Wood Research, notably Thomas Schwarz for the provision of ICP-OES and support.

\section{Author details}

${ }^{1}$ Applied Plant Ecology, Biocenter Klein Flottbek, Universität Hamburg, Ohnhorstraße 18, 22609 Hamburg, Germany. ${ }^{2}$ Institute for Soil Science, CEN, Universität Hamburg, Allende-Platz 2, 20146 Hamburg, Germany.

Received: 23 September 2014 Accepted: 27 November 2014 Published online: 17 January 2015

\section{References}

Alef K, Nannipieri P (1995) Methods in applied soil microbiology and biochemistry. Academic Press, London

Alfani A, Baldantoni D, Maisto G, Bartoli G, de Virzo SA (2000) Temporal and spatial variation in C, N, S and trace element contents in the leaves of Quercus ilex within the urban are of Naples. Environ Pollut 109(1):119-129

ANKOM (2014a) ANKOM 2000 fiber analyzer- Operator's Manual., https://ankom. com/media/documents/A2000series_Manual_RevE_083011.pdf. Accessed 09. Dec 2014

ANKOM (2014b) Method for Determining Acid Detergent Lignin in Beakers., https://ankom.com/media/documents/ADL_beakers.pdf. Accessed 09. Dec 2014

Berg B, McClaugherty C (2008) Plant litter. Decomposition, humus formation, carbon sequestration, 2nd edn. Springer, Berlin

Carreiro M, Howe K, Parkhurst D, Pouyat R (1999) Variation in quality and decomposability of red oak leaf litter along an urban-rural gradient. Biol Fertil Soils 30(3):258-268

Carreiro M, Pouyat R, Tripler C, Zhu W (2009) Carbon and nitrogen cycling in soils of remnant forests along urban-rural gradients: case studies in the New York metropolitan area and Louisville, Kentucky. In: McDonnell M, Hahs A, Breuste
J (eds) Ecology of cities and towns: a comparative approach. Cambridge University Press, Cambridge, pp 308-328

Carreras HA, Cañas MS, Pignata ML (1996) Differences in responses to urban air pollutants by Ligustrum lucidum Ait. and Ligustrum lucidum Ait. f. tricolor (Rehd.) Rehd. Environ Pollut 93(2):211-218

Churkina G, Brown D, Keoleian G (2010) Carbon stored in human settlements: the conterminous United States. Glob Chang Biol 16(1):135-143, doi:10.1111/ j.1365-2486.2009.02002.x

Cotrufo MF, de Santo AV, Alfani A, Bartoli G, de Cristofaro A (1995) Effects of urban heavy metal pollution on organic matter decomposition in Quercus ilex L. woods. Environ Pollut 89(1):81-87

Coûteaux M, Bottner P, Berg B (1995) Litter decomposition, climate and litter quality. Tree 10(2):63-66

Czerniawska-Kusza I, Kusza G, Dużyński M (2004) Effect of deicing salts on urban soils and health status of roadside trees in the Opole region. Environ Toxicol 19(4):296-301

Fenn ME, Dunn PH (1989) Litter decomposition across an air-pollution gradient in the San Bernardino Mountains. Soil Sci Soc Am J 53(5):1560-1567

Freie und Hansestadt Hamburg (2012) Behörde für Gesundheit und Verbraucherschutz- Institut für Hygiene und Umwelt- Hamburger Luftmessnetz (HALm)- Ozonwarndienst- Hamburger Luftmessnetz- Ergebnisse 2011

Grimm NB, Faeth SH, Golubiewski NE, Redman CL, Wu J, Bai X, Briggs JM (2008) Global change and the ecology of cities. Science 319(5864):756-760, doi:10.1126/science.1150195

Hoffmann P, Schlünzen K (2010) Das Hamburger Klima. In: Poppendieck H, Bertram H, Brandt I, Engelschall B, Prondzinski J (eds) Der Hamburger Pflanzenatlas. Von A bis Z, 1st edn. Dölling und Galitz, München

Isermeyer H (1952) Eine einfache Methode zur Bestimmung der Bodenatmung und der Karbonate im Boden. Zeitschrift für Pflanzenernährung, Düngung, Bodenkunde 56(1-3):26-38

Kagata H, Ohgushi T (2013) Home-field advantage in decomposition of leaf litter and insect frass. Popul Ecol 55(1):69-76, doi:10.1007/s10144-012-0342-5

McDonnell M, Pickett S (1990) Ecosystem structure and function along urbanrural gradients. An unexploited opportunity for ecology. Ecology 71 (4):1232-1237

Nikula S, Vapaavuori E, Manninen S (2010) Urbanization-related changes in European aspen (Populus tremula L.): leaf traits and litter decomposition. Environ Pollut 158(6):2132-2142, doi:10.1016/j.envpol.2010.02.025

Oke T (1973) City size and the urban heat island. Atmos Environ 7(8):769-779

Pavao-Zuckerman MA, Coleman DC (2005) Decomposition of chestnut oak (Quercus prinus) leaves and nitrogen mineralization in an urban environment. Biol Fertil Soils 41(5):343-349, doi:10.1007/s00374-005-0841-z

Post R, Beeby A (1996) Activity of the microbial decomposer community in metal-contaminated roadside soils. J Appl Ecol 33(4):703-709

Potere D, Schneider A (2007) A critical look at representations of urban areas in global maps. GeoJournal 69(1-2):55-80, doi:10.1007/s10708-007-9102-z

Pouyat RV, Carreiro MM (2003) Controls on mass loss and nitrogen dynamics of oak leaf litter along an urban-rural land-use gradient. Oecologia 135:288-298

Pouyat RV, McDonnell MJ, Pickett STA (1997) Litter decomposition and nitrogen mineralization in oak stands along an urban-to-rural land use gradient. Urban Ecosystems 1(2):117-131, doi:10.1023/A:1018567326093

Prescott CE (2010) Litter decomposition: what controls it and how can we alter it to sequester more carbon in forest soils? Biogeochemistry 101(1-3):133-149

Raciti S, Hutyra L, Rao P, Finzi A (2012) Inconsistent definitions of "urban" result in different conclusions about the size of urban carbon and nitrogen stocks. Ecol Appl 22(3):1015-1035

Raich J, Schlesinger W (1992) The global carbon dioxide flux in soil respiration and its relationship to vegetation and climate. Tellus 44(2):81-99

Schlünzen KH, Hoffmann P, Rosenhagen G, Riecke W (2010) Long-term changes and regional differences in temperature and precipitation in the metropolitan area of Hamburg. Int J Climatol 30(8):1121-1136, doi:10.1002/joc.1968

Statistisches Amt für Hamburg und Schleswig-Holstein (2012) Hamburger Stadtteilprofile. http://www.statistik-nord.de/fileadmin/download/Stadtteil_Profile_html5/atlas.html. Accessed 7 Oct 2013

Statistisches Amt für Hamburg und Schleswig-Holstein (2013) Statistisches Jahrbuch 2012/2013. Hamburg

Steinberg DA, Pouyat RV, Parmelee RW, Groffman PM (1997) Earthworm abundance and nitrogen mineralization rates along an urban-rural land use gradient. Soil Biol Biochem 29(3-4):427-430

Swift MJ, Heal OW, Anderson JM (1979) Decomposition in terrestrial ecosystems. Studies in ecology, vol 5. University of California Press, Berkeley 
UN (2011) World Urbanization Prospects The 2011 Revision Highlights., http://de. slideshare.net/undesa/wup2011-highlights. Accessed 09.Dec 2014

Wiesner S, Eschenbach A, Ament F (2014) Urban air temperature anomalies and their relation to soil moisture observed in the city of Hamburg. Meteorol Z 23(2):143-15

Wittig R, Sukopp H, Klausnitzer B (1998) Die ökologische Gliederung der Stadt. In: Sukopp H, Wittig R (eds) Stadtökologie. Ein Fachbuch für Studium und Praxis, 2nd edn. G. Fischer, Stuttgart, pp 316-372

Zirkle G, LAL R, Augustin B, Follett R (2012) Modeling carbon sequestration in the U.S. residential landscape. In: Lal R, Augustin B (eds) Carbon sequestration in urban ecosystems. Springer Science + Business Media B.V, Dordrecht, pp $265-276$

Submit your manuscript to a SpringerOpen ${ }^{\circ}$ journal and benefit from:

- Convenient online submission

- Rigorous peer review

- Immediate publication on acceptance

- Open access: articles freely available online

- High visibility within the field

- Retaining the copyright to your article

Submit your next manuscript at $\gg$ springeropen.com 